\title{
A!
}

This is an electronic reprint of the original article.

This reprint may differ from the original in pagination and typographic detail.

Karimi, Nazanin; Kunwar, Puskal; Hassinen, Jukka; Ras, Robin H A; Toivonen, Juha

\section{Micropatterning of silver nanoclusters embedded in polyvinyl alcohol films}

\section{Published in:}

Optics Letters

DOI:

10.1364/OL.41.003627

Published: 01/08/2016

Document Version

Peer reviewed version

Please cite the original version:

Karimi, N., Kunwar, P., Hassinen, J., Ras, R. H. A., \& Toivonen, J. (2016). Micropatterning of silver nanoclusters embedded in polyvinyl alcohol films. Optics Letters, 41(15), 3627-3630. https://doi.org/10.1364/OL.41.003627

This material is protected by copyright and other intellectual property rights, and duplication or sale of all or part of any of the repository collections is not permitted, except that material may be duplicated by you for your research use or educational purposes in electronic or print form. You must obtain permission for any other use. Electronic or print copies may not be offered, whether for sale or otherwise to anyone who is not an authorised user. 


\title{
Micropatterning of Silver Nanoclusters Embedded in Polyvinyl Alcohol Films
}

\author{
Nazanin Karimi, ${ }^{1}$ Puskal KunWar, ${ }^{1,}{ }^{*}$ Jukka Hassinen, ${ }^{2}$ Robin H. A. Ras, ${ }^{2}$ \\ AND JUHA TOIVONEN ${ }^{1}$ \\ ${ }^{1}$ Department of Physics, Tampere University of Technology, Tampere, 33101, Finland \\ ${ }^{2}$ Department of Applied Physics, Aalto University, Espoo, 02150, Finland \\ *Corresponding author: puskal.kunwar@tut.fi
}

Received XX Month XXXX; revised XX Month, XXXX; accepted XX Month XXXX; posted XX Month XXXX (Doc. ID XXXXX); published XX Month XXXX

\begin{abstract}
Direct laser writing has been utilized to fabricate highly photostable fluorescent nanocluster microstructures in organic polymer poly(methacrylic acid), where the carboxyl functional group is reported to play a vital role in nanocluster stabilization. In this paper, we demonstrate that not only polymer containing carboxyl functional group, but also polymer comprising hydroxyl group, namely polyvinyl alcohol (PVA) can act as an appropriate stabilizer matrix for laser-induced synthesis and patterning of silver nanoclusters. The as-formed nanoclusters in PVA film exhibit broadband emission and photostability comparable to the nanoclusters formed in poly(methacrylic acid) polymer. As PVA is widely used, nontoxic, biocompatible and biodegradable polymer; the technique of patterning fluorescent nanoclusters in PVA thin films is expected to find numerous applications in fields like fluorescence imaging, biolabeling, and sensing. (C) 2015 Optical Society of America
\end{abstract}

OCIS codes: (220.0220) Optical design and fabrication; (220.4610) Optical fabrication; (220.4000) Microstructure fabrication; (210.0120) Optical data storage; (160.0160) Materials; (160.5470) Polymers; (250.5230) Photoluminescence; (160.2540) Fluorescent and luminescent materials.

http://dx.doi.org/10.1364/OL.99.099999

Metal nanoclusters (NCs) have attracted significant interest as they exhibit different physical, chemical and electronic properties compared to metal nanoparticles or bulk metal [1]. Composed of a few to a few hundred atoms, they provide a missing link between isolated metal atoms and nanoparticles [2,3]. Nanoclusters exhibit molecule-like properties such as discrete electronic transitions and intense fluorescence [1-4]. Due to the bright fluorescence with excellent photostability, metal NCs, such as gold and silver NCs, can be utilized for many applications including single-molecule studies, fluorescence imaging, fluorescence sensing, optical data storage, and labeling [1,3-5].
Silver NCs are often synthesized by dissolving silver salt in a solvent, followed by the reduction of silver ions to the zero-valent state. The reduction of silver ions can be achieved by using chemical reductants [6,7], $\gamma$-rays [8], ultrasound [9], ultraviolet [10] or visible light $[11,12]$. However, the synthesis of NCs is usually difficult, as they strongly tend to aggregate. The aggregation results in the formation of larger particles that no longer exhibit molecule-like properties such as fluorescence [1315]. Therefore, in order to preserve these attractive properties of NCs, it is necessary to stabilize their growth. The stabilization can be accomplished by reducing the silver ions in encapsulating scaffolds such as polymers [13], dendrimers [16] and DNA [17,18]. The role of stabilizing molecules in the properties of NCs is significant, as they alter the electronic structure of the complex [19]. The encapsulated NCs exhibit more stability against photobleaching in comparison with organic dyes $[4,13,20]$. Hence, due to their photostability, low toxicity and biocompatibility, silver NCs synthesized in organic matrices could be excellent substitutes for organic dyes and semiconductor quantum dots in biolabeling applications [1,3-5]. Multi-photon direct laser writing (DLW), a technique for the fabrication of three-dimensional micro/nanostructures in photosensitive materials [21,22], has also shown to be a promising technique to form and stabilize silver NCs. Using multi-photon DLW, silver NCs microstructures have been fabricated in glass [23], zeolites [24], and poly(methacrylic acid) (PMAA) films [13]. However, multi-photon DLW requires an expensive excitation source such as a femtosecond or picosecond laser that delivers a high laser pulse intensity. On the contrary, single photon DLW utilizes low-cost continuous wave (CW) lasers and is also shown to form silver nanoclusters in PMAA films with intensity much lower compared to multi-photon DLW. Thus, the use of single photon DLW greatly reduces the expenses and complexity of the technique $[25,26]$.

Similar techniques of laser reduction have been used to fabricate metallic structures made of nanoparticles, for example, printing of $\mathrm{Cu}$ electrodes using direct laser patterning, fabrication of three dimensional gold microstructures and disconnected threedimensional silver nanostructures [27-29]. However, these studies 
do not report the formation of fluorescent nanoclusters. For the formation of nanoclusters, an encapsulating agent such as PMAA polymer is necessary. PMAA is a well-known stabilizing agent for encapsulating brightly fluorescent silver nanoclusters both in solution and thin film. The PMAA polymer has a strong affinity for silver ions and silver surfaces due to the presence of carboxyl functional group. Therefore, it is believed that the presence carboxyl functional group in this polymer prevents the growth of nanoclusters to large nanoparticles $[9,13]$.

In this paper, we demonstrate the formation and stabilization of photostable fluorescent Ag NCs for the first time in polyvinyl alcohol (PVA) films using the single photon DLW technique. PVA contains hydroxyl functional groups instead of carboxyl functional groups in PMAA. Further, PVA is cost-effective and widely used polymer with excellent film-forming ability [30,31], and features such as biocompatibility, biodegradability, and non-toxicity make PVA an attractive material for biomedical and pharmaceutical applications [30,32,33]. PVA has also been used to stabilize metal nanoparticles [34-36]. However, we used a focused laser beam to photo-reduce silver ions to form nanoclusters locally within a spincoated PVA polymer film. The silver NCs were studied using fluorescence microscopy and spectroscopy to obtain detailed information about their fluorescence properties and photostability. Furthermore, we characterized the laser written structures in detail using atomic force microscopy (AFM). Our findings show that Ag NCs stabilized in PVA films emit broadband fluorescence at visible wavelengths with excellent photostability.

For the experiments, we prepared $3 \mathrm{w}-\%$ of PVA aqueous solution by dissolving the PVA powder (Sigma-Aldrich), with molecular weight between 89000 and $98000 \mathrm{~g} / \mathrm{mol}$ in water. Varied amounts of silver nitrate (Sigma-Aldrich, $\geq 99 \%$ ) was mixed with the PVA solution to obtain Ag/PVA samples with different concentrations (from $21 \mathrm{w} / \mathrm{w}$ to $62 \mathrm{w} / \mathrm{w}$ ). These values correspond to $5 \%$ and $16 \%$ when expressed in terms of ratio of number of $\mathrm{Ag}$ atoms to number of hydroxide $(\mathrm{OH})$. The mixtures were then spin-coated on glass substrates to obtain thin films of PVA containing silver. The films were exposed to the writing laser beam with wavelength $\left(\lambda_{\text {dlw }}\right)$ of $405 \mathrm{~nm}$ using a DLW setup $[13,25]$ where the sample was scanned against the fixed laser beam. We acquired fluorescence images and emission spectra of the written structures through a custom built microscope and spectrometer, described in our earlier work [13]. Additionally, topography of the structures was studied using a Veeco Dimension 5000 AFM with a Nanoscope V controller. The AFM was also used to estimate the thickness of the PVA films by scanning the tip perpendicular to a scratch made by a scalpel.

We obtained significantly bright fluorescence from the areas of Ag/PVA samples that were irradiated with the laser beam. Figure 1(a) illustrates the fluorescence image of an array of lines fabricated with laser intensity ( $\mathrm{I}_{\mathrm{dlw}}$ ) of 6 $\mathrm{MW} / \mathrm{cm}^{2}$, and scanning speed of $5 \mu \mathrm{m} / \mathrm{s}$ in a Ag/PVA sample with $10 \% \mathrm{Ag} / \mathrm{OH}$ ratio. The fluorescence image was obtained by exciting the written structures with a LED light source of wavelength $\left(\lambda_{\text {exc }}\right)$ of $470 \mathrm{~nm}$ and excitation intensity ( $\mathrm{I}_{\mathrm{exc}}$ ) of $100 \mathrm{~W} / \mathrm{cm}^{2}$, which is considerably lower

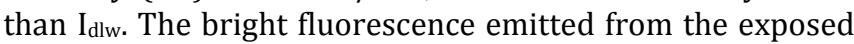
areas compared to the unexposed regions is attributed to the formation and stabilization of silver NCs through the DLW. This contrast can be also seen in the fluorescence intensity profile plotted across the fabricated lines (Figure 1(b)), with an average line breadth of $500 \mathrm{~nm}$.

To further investigate the origin of the fluorescence emitted from the written structures in Ag/PVA films, we acquired emission spectra from the written structures on samples with different Ag/PVA concentration ( $5 \%$ to $12.5 \% \mathrm{Ag} / \mathrm{OH}$ ratio). The Ag/PVA samples with ratio of more than $12.5 \%$ exhibited undesired crystallization of silver nitrate and were omitted from the studies. The crystallization most likely happened due to supersaturated solution of $\mathrm{AgNO}_{3}$ in PVA solution. For all the experiments, the writing conditions, i.e. laser writing intensity and the scanning speed were fixed to $6 \mathrm{MW} / \mathrm{cm}^{2}$ and $5 \mu \mathrm{m} / \mathrm{s}$, respectively. Fluorescence emission spectra were recorded by exciting the written structures with a $473 \mathrm{~nm}$ laser beam having excitation power of $300 \mathrm{~W} / \mathrm{cm}^{2}$. Figure 2 shows the broad emission spectra of the structures with an emission maximum at around $550 \mathrm{~nm}$. The cutoff at wavelengths shorter than $500 \mathrm{~nm}$ is due to the emission filter used in order to block the excitation light. In the spectra, we also observed sharp peaks at around $510 \mathrm{~nm}$. This is attributed to an enhanced Raman scattering effect due to strong charge-transfer interactions of NCs with the surrounding polymer molecules and is discussed in detail in our earlier publications $[13,37]$. Figure 2 also indicates that the fluorescence intensity increases with increasing silver concentration: the highest and lowest intensities were achieved for Ag/PVA samples with $12.5 \%$ and $5 \% \mathrm{Ag} / \mathrm{OH}$ ratio, respectively. The inset image of Figure 2 illustrates the concentration dependence of the fluorescence intensity at $560 \mathrm{~nm}$. Moreover, we were unable to write structures in the sample with no silver content. These findings show that the fluorescence is primarily related to the presence of silver in the polymer $[13,25]$. The fluorescence from the written structures exhibit very similar characteristics to nanoclusters formed at solution [12,38] and PMAA thin films [13,25]. Most importantly, the fluorescence from the written structures strongly depends on the silver concentration.

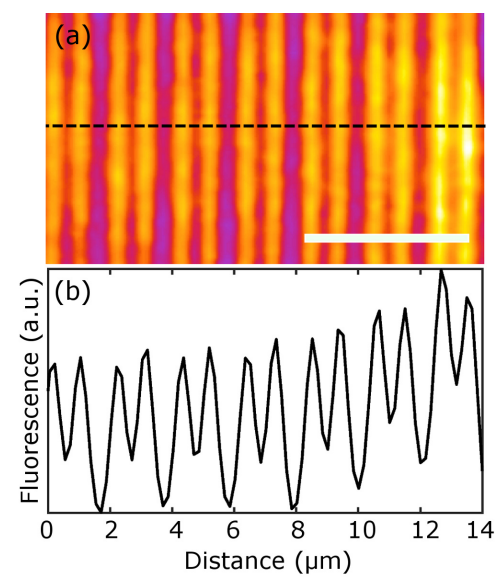

Fig. 1. a) Fluorescence image of laser written lines in Ag/PVA sample with $10 \% \mathrm{Ag} / \mathrm{OH}$ ratio $\left(\mathrm{I}_{\mathrm{dlw}}=6 \mathrm{MW} / \mathrm{cm}^{2}, \lambda_{\mathrm{dlw}}=405 \mathrm{~nm}, \mathrm{I}_{\mathrm{exc}}=100\right.$ $\mathrm{W} / \mathrm{cm}^{2}, \lambda_{\text {exc }}=470 \mathrm{~nm}$ ). Scale bar $=5 \mu \mathrm{m}$. (b) Fluorescence intensity profile across the dashed line marked in (a).

Silver nanoparticles larger than $2 \mathrm{~nm}$ exhibit collective oscillations of conduction electrons upon interaction with light and typically do not possess fluorescence. There are 
few reports about strong photoluminescence of silver nanoparticles, however, it is assumed in the reports that the fluorescence is likely produced from surface bound nanoclusters or angstrom-size domains within nanoparticles $[39,40]$. Since the fluorescence from the written structures strongly depends on the silver concentration and large silver nanoparticles are not fluorescent, we conclude that silver nanoclusters having size less than $2 \mathrm{~nm}$ are the main source of fluorescence in our laser written PVA structures. Since the fluorescence from the written structures strongly depends on the silver concentration and large silver nanoparticles are not fluorescent, we conclude that silver nanoclusters having size less than $2 \mathrm{~nm}$ are the main source of fluorescence in our laser written PVA structures.

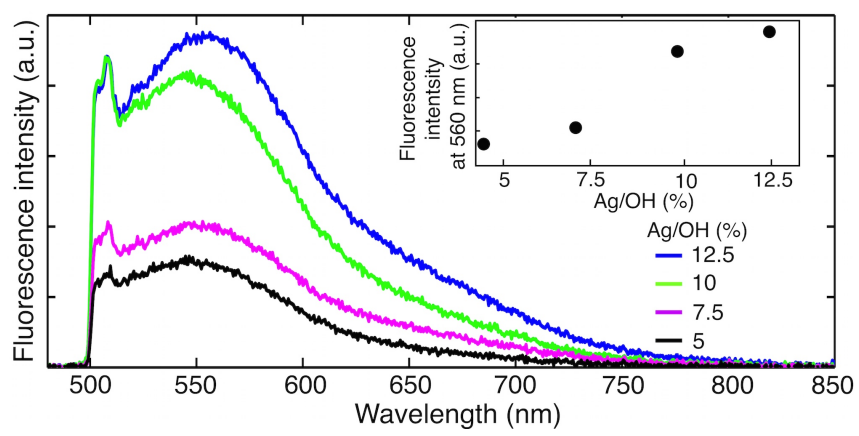

Fig. 2. Fluorescence emission spectra of laser-written silver NCs in $\mathrm{Ag} / \mathrm{PVA}$ films with $\mathrm{Ag} / \mathrm{OH}$ ratios of $5 \%$ to $12.5 \%\left(\lambda_{\mathrm{exc}}=473 \mathrm{~nm}\right)$. The inset image illustrates the dependence of the fluorescence intensity on Ag concentration at $560 \mathrm{~nm}$.

To characterize the microstructures written on the $\mathrm{Ag} / \mathrm{PVA}$ thin film in detail, we studied the topography of the surface using AFM. Figure 3 shows the AFM images of the structures written with different laser writing intensities and the corresponding line profiles along the region marked by red in the AFM images. The depths observed in line profiles manifests the formation of 3D grooves at the positions of the laser-written structures. The grooves made by laser intensities of $6 \mathrm{MW} / \mathrm{cm}^{2}, 9 \mathrm{MW} / \mathrm{cm}^{2}$, and 12 $\mathrm{MW} / \mathrm{cm}^{2}$ had depths of $32 \mathrm{~nm}, 35 \mathrm{~nm}$, and $38 \mathrm{~nm}$, respectively. Obtained from the AFM analysis of a scratch made by a scalpel, the Ag/PVA film had a thickness of about $58 \mathrm{~nm}$. Comparing the values measured for the depth of the grooves and the film thickness suggests that the DLW process ablates a considerable amount of the material in the exposed areas. However, the fluorescence signal was detected precisely from the regions exposed to the writing laser beam (Figure 1). This result suggests the presence of the silver NCs in the written structures despite the material ablation. Moreover, the line breadths of the structures written with laser intensities of $6 \mathrm{MW} / \mathrm{cm}^{2}, 9 \mathrm{MW} / \mathrm{cm}^{2}$, and $12 \mathrm{MW} / \mathrm{cm}^{2}$ were estimated to be $380 \mathrm{~nm}, 600 \mathrm{~nm}$, and $700 \mathrm{~nm}$, respectively. Further, the surface roughness of the structures was found to be around $2 \mathrm{~nm}$.

Finally, we investigated the photostability of the fluorescent silver NCs under strong illumination conditions. Microstructures written with $I_{\mathrm{dlw}}$ of $6 \mathrm{MW} / \mathrm{cm}^{2}\left(\lambda_{\mathrm{dlw}}=405\right.$ $\mathrm{nm}$ ) on $\mathrm{Ag} / \mathrm{PVA}$ sample with $10 \% \mathrm{Ag} / \mathrm{OH}$ ratio were excited by a $473 \mathrm{~nm}$ laser diode, with laser intensities of $60 \mathrm{~W} / \mathrm{cm}^{2}$, $300 \mathrm{~W} / \mathrm{cm}^{2}$, and $600 \mathrm{~W} / \mathrm{cm}^{2}$. Fluorescence spectra were recorded with an interval of $1 \mathrm{~s}$, and the total fluorescence intensity was estimated by integrating the area under each spectrum. The photobleaching curves shown at Figure 4 depict that the written structures bleached to $53 \%, 30 \%$ and $15 \%$ of its initial intensity in $300 \mathrm{~s}$ when they were irradiated with $60 \mathrm{~W} / \mathrm{cm}^{2}, 300 \mathrm{~W} / \mathrm{cm}^{2}$, and $600 \mathrm{~W} / \mathrm{cm}^{2}$, respectively.

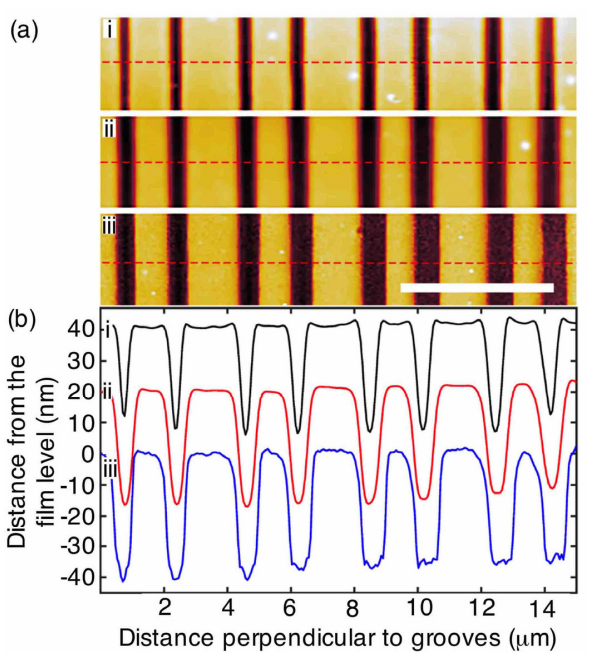

Fig. 3. (a) AFM images of the structures written with Idlw of (i) 6 $\mathrm{MW} / \mathrm{cm}^{2}$, (ii) $9 \mathrm{MW} / \mathrm{cm}^{2}$, and (iii) $12 \mathrm{MW} / \mathrm{cm}^{2}$ in $\mathrm{Ag} / \mathrm{PVA}$ samples with $10 \% \mathrm{Ag} / \mathrm{OH}$ ratio. Scale bar $=5 \mu \mathrm{m}$. (b) Line-cut topography profiles of the structures across the dashed lines marked in (a). The line width of the grooves measured from the line-cut topography profiles are (i) $380 \mathrm{~nm}$, (ii) $600 \mathrm{~nm}$, and (iii) $700 \mathrm{~nm}$. For clarity, the line profiles of $\mathrm{i}$ and ii are vertically shifted by $40 \mathrm{~nm}$ and $20 \mathrm{~nm}$, respectively.

We further studied the photobleaching of nanoclusters by employing a double exponential decay $\left(y=a \times \exp \left(-t / \tau_{1}\right)\right.$ $\left.+b \times \exp \left(-t / \tau_{2}\right)\right)$ fitting for the bleaching curves (Figure 4), where $a$ and $b$ are amplitude parameters, $t$ is time, and $\tau_{1}$ and $\tau_{2}$ represent bleaching time constants. Table I summarizes the acquired values for $\tau_{1}$ and $\tau_{2}$ when structures were excited with the three different intensities. Obtaining two different time constants for the bleaching indicates two different populations of fluorescent NCs. The first population dies out quite fast with the time constant of $\tau_{1}$, while the other population shows considerable photostability with much larger time constant of $\tau_{2}$. Further, we observed that there are no changes in the shape of the recorded fluorescence spectra during the bleaching (data not shown). The bleaching results demonstrate that the fabricated nanoclusters in PVA are remarkably photostable when compared to conventional organic dyes such as Rhodamine 6G under the similar illumination conditions $[13,25]$. The written NC structures are still brightly fluorescent after hundreds of readouts. It is worth noticing that the illumination conditions in our experiments are harsh compared to normal solar irradiance on Earth which 
is about $0.1 \mathrm{~W} / \mathrm{cm}^{2}$ [41]. The photoluminescence property and photostability of as-formed nanoclusters are very similar to that of silver nanoclusters in PMAA [13]. PVA is widely used industrial polymer offering a cost efficient matrix for fluorescent nanoclusters.

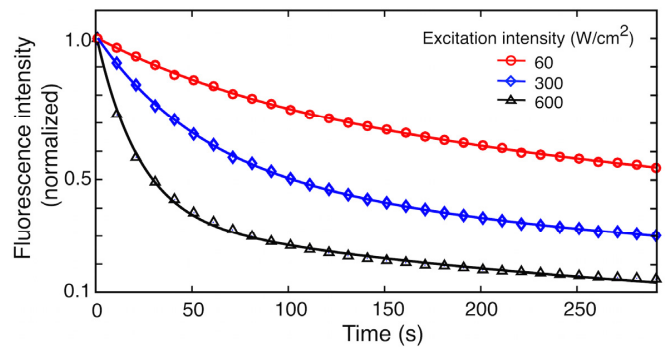

Fig. 4. Fluorescence photobleaching curves corresponding to the structures written with $\mathrm{I}_{d \mathrm{lw}}$ of $6 \mathrm{MW} / \mathrm{cm}^{2}\left(\lambda_{\text {dlw }}=405 \mathrm{~nm}\right) \mathrm{in} \mathrm{Ag} / \mathrm{PVA}$ sample with $10 \% \mathrm{Ag} / \mathrm{OH}$ ratio. The sample is excited with a $473 \mathrm{~nm}$ laser, and $\mathrm{I}_{\mathrm{exc}}$ of $60 \mathrm{~W} / \mathrm{cm}^{2}$ (red), $300 \mathrm{~W} / \mathrm{cm}^{2}$ (blue), and $600 \mathrm{~W} / \mathrm{cm}^{2}$ (black). The solid lines represent double-exponential fits to the data points (open symbols).

Table 1. Bleaching time constants $\tau_{1}$ and $\tau_{2}$ when written structures are excited with a laser with three different intensities at $473 \mathrm{~nm}$ wavelength

\begin{tabular}{ccc}
\hline \hline $\mathrm{I}_{\mathrm{exc}}\left(\mathrm{W} / \mathrm{cm}^{2}\right)$ & $\tau_{1}(\mathrm{~s})$ & $\tau_{2}(\mathrm{~s})$ \\
\hline 60 & 103 & 990 \\
300 & 52 & 507 \\
600 & 23 & 300 \\
\hline \hline
\end{tabular}

In conclusion, we have successfully fabricated fluorescent microstructures comprising of silver NCs for the first time in PVA films using DLW with a cost-effective laser diode. The written structures were found to be highly photostable, as compared to previously studied NCs and organic dyes, confirming that PVA film is an appropriate matrix to form and stabilize silver NCs. We anticipate that this technique can be extended to the fabrication of various metal NCs in different polymer matrices for numerous applications like optical data storage, imaging, biolabeling, and sensing.

P.K. is grateful for the support from the Graduate School of Tampere University of Technology. This work made use of the Aalto University Nanomicroscopy Center (Aalto-NMC) premises.

\section{REFERENCES}

1. H.-T. Sun and Y. Sakka, Sci. Technol. Adv. Mater. 15, 014205 (2014).

2. H. Xu and K. S. Suslick, Adv. Mater. 22, 1078 (2010).

3. I. Díez and R. H. A. Ras, Nanoscale 3, 1963 (2011).

4. C.-A. J. Lin, C.-H. Lee, J.-T. Hsieh, H.-H. Wang, J. K. Li, J.-L. Shen, W.-H. Chan, H.-I. Yeh, and W. H. Chang, J. Med. Biol. Eng. 29, 276 (2009).

5. I. Díez, R. H. A. Ras, M. I. Kanyuk, and A. P. Demchenko, Phys. Chem. Chem. Phys. 15, 979 (2013).
6. I. Chakraborty, A. Govindarajan, J. Erusappan, A. Ghosh, T. Pradeep, B. Yoon, R. L. Whetten, and U. Landman, Nano Lett. 12, 5861 (2012).

7. J. T. Petty, S. P. Story, J.-C. Hsiang, and R. M. Dickson, J. Phys. Chem. Lett. 4 $1148(2013)$

8. B. G. Ershov and A. Henglein, J. Phys. Chem. B 102, 10663 (1998).

9. H. Xu and K. S. Suslick, ACS Nano 4, 3209 (2010).

10. J. Zhang, S. Xu and E. Kumacheva, Adv. Mater. 17, 2336 (2005).

11. J. P. Wilcoxon and B. L. Abrams, Chem. Soc. Rev. 35, 1162 (2006).

12. I. Díez, M. Pusa, S. Kulmala, H. Jiang, A. Walther, A. S. Goldman, A. H. E. Müller, O. Ikkala and R. H. A. Ras, Angew. Chem. Int. Ed. 48, 2122 (2009).

13. P. Kunwar, J. Hassinen, G. Bautista, R. H. A. Ras, and J. Toivonen, ACS Nano 8, 11165 (2014).

14. J. Li, J.-J. Zhu, and K. Xu, Trends Anal. Chem. 58, 90 (2014).

15. G. Schmid, and L. F. Chi, Adv. Mater. 10, 515 (1998).

16. J. Zheng, J. T. Petty, and R. M. Dickson, J. Am. Chem. Soc. 125, 7780 (2003).

17. E. G. Gwinn, P. O'Neill, A. J. Guerrero, D. Bouwmeester, and D. K. Fygenson, Adv. Mater. 20, 279 (2008).

18. B. Corain, G. Schmid, and N. Toshima, Metal Nanoclusters in Catalysis and Materials Science (Elsevier, Amsterdam, 2008) pp. 22.

19. P. Jena and A. W. Castleman, Nanoclusters A Bridge across Disciplines (Elsevier, Amsterdam, 2010) p. 28.

20. X. L. Guével, B. Hötzer, G. Jung, K. Hollemeyer, V. Trouillet, and M. Schneider, J. Phys. Chem. C 115, 10955 (2011).

21. S. Kawata, H. Sung, T. Tanaka, and K. Takada, Nature 412, 697(2001).

22. P. Kunwar, J. Toivonen, M. Kauranen, and G. Bautista, Opt. Express 24 9353 (2016).

23. M. Bellec, A. Royon, K. Bourhis, J. Choi, B. Bousquet, M. Treguer, T. Cardinal, J.-J. Videau, M. Richardson, and L. Canioni, J. Phys. Chem. C 114, 15584 (2010).

24. G. De Cremer, B. F. Sels, J.-I. Hotta, M. B. J. Roeffaers, E. Bartholomeeusen, E. Coutiño-Gonzalez, V. Valtchev, D. E. De Vos, T. Vosch, and J. Hofkens, Adv. Mater. 22, 957 (2010).

25. P. Kunwar, J. Hassinen, G. Bautista, R. H. A. Ras, and J. Toivonen, Scientific reports 6, 23998(2016).

26. P. Kunwar, L. Turquet, J. Hassinen, R.H. A. Ras, J. Toivonen, and G. Bautista, Opt. Mater. Express 6, 946 (2016).

27. B. Kang, S. Han, J. Kim, S. Ko, and M. Yang, J. Phys. Chem. C 115, 2366423670 (2011).

28. E. Blasco, J. Müller, P. Müller, V. Trouillet, M. Schön, T. Scherer, C. B.Kowollik, and M. Wegener, Adv. Mater. 28, 3592-3595 (2016).

29. K. Vora, S. Y. Kang, S. Shukla and E. Mazur, Appl. Phys. Lett. 100, 063120 (2012).

30. J. Wang and L. Ye, Composites: Part B 69, 389 (2015).

31. R. Chandra and R. Rustigi, Prog. Polym. Sci. 23, 1273 (1998).

32. M. I. Baker, S. P. Walsh, Z. Schwartz, and B. D. Boyan, J. Biomed. Mater. Res. Part B 100B, 1451 (2012).

33. S. Ghoshal, P. Denner, S. Stapf, and C. Mattea, Macromolecules 45, 1913 (2012).

34. N. Mahanta and S. Valiyaveettil, RSC Adv. 2, 11389 (2012).

35. D. Pencheva, R. Bryaskova, and T. Kantardjiev, Mater. Sci. Eng. C 32, 2048 (2012)

36. E. Filippo, A. Serra, and D. Manno, Sens. Actuator B-Chem 138, 625 (2009).

37. L. Peyser-Capadona, J. Zheng, J. I. González, T.-H. Lee, S. A. Patel, and R. M. Dickson, Phys. Rev. Lett. 94, 058301 (2005).

38. L. Shang and S. Dong, Chem. Commun. 1088-1090 (2008).

39. J. Zheng, Y. Ding, B. Z. Tian, Z. L. Wang and X. W. Zhuang, J. Am. Chem. Soc. 130, 10472-10473 (2008).

40. L. Maretti, P. S. Billone, Y. Liu and J. C. Scaiano, J. Am. Chem. Soc. 131, 13972-13980 (2009).

41. R. C. Willson, and A. V. Mordvinov, Geophys. Res. Lett. 30, 21-23 (2003). 


\section{References including titles}

1. H.-T. Sun and Y. Sakka, "Luminescent metal nanoclusters: controlled synthesis and functional applications" Science and Technology of Advanced Material 15, 014205 (2014).

2. H. Xu and K. S. Suslick, "Water-Soluble Fluorescent Silver Nanoclusters"

Advanced Materials 22, 1078-1082 (2010).

3. I. Díez and R. H. A. Ras, "Fluorescent silver nanoclusters" Nanoscale 3, 1963-1970 (2011).

4. C.-A. J. Lin, C.-H. Lee, J.-T. Hsieh, H.-H. Wang, J. K. Li, J.-L. Shen, W.-H. Chan, H.-I. Yeh, and W. H. Chang, "Synthesis of Fluorescent Metallic Nanoclusters Toward Biomedical Application: Recent Progress and Present Challenges" Journal of Medical and Biological Engineering 29, 276-283 (2009).

5. I. Díez, R. H. A. Ras, M. I. Kanyuk, and A. P. Demchenko, “On heterogeneity in fluorescent few-atom silver nanoclusters" Physical Chemistry Chemical Physics 15, 979-985 (2013).

6. I. Chakraborty, A. Govindarajan, J. Erusappan, A. Ghosh, T. Pradeep, B. Yoon, R. L. Whetten, and U. Landman, "The superstable 25-kDa monolayer protected silver nanoparticle: Measurements \& interpretation as an icosahedral $\mathrm{Ag}_{152}\left(\mathrm{SCH}_{2} \mathrm{CH}_{2} \mathrm{Ph}\right)_{60}$ cluster" Nano Letters 12, 5861-5866 (2012)

7. J. T. Petty, S. P. Story, J.-C. Hsiang, and R. M. Dickson, "DNA-Templated Molecular Silver Fluorophores" Journal of Physical Chemistry Letters 4, 1148-1155 (2013).

8. B. G. Ershov and A. Henglein, "Reduction of $\mathrm{Ag}^{+}$on Polyacrylate Chains in Aqueous Solution" Journal of Physical Chemistry B 102, 10663-10666 (1998).

9. H. Xu and K. S. Suslick, "Sonochemical Synthesis of Highly Fluorescent Ag Nanoclusters" ACS Nano 4, 3209-3214 (2010).

10. J. Zhang, S. Xu and E. Kumacheva, "Photogeneration of Fluorescent Silver Nanoclusters in Polymer Microgels" Advanced Materials 17, 2336-2340 (2005).

11. J. P. Wilcoxon and B. L. Abrams, "Synthesis, structure and properties of metal nanoclusters" Chemical Society Reviews 35, 1162-1194 (2006).

12. I. Díez, M. Pusa, S. Kulmala, H. Jiang, A. Walther, A. S. Goldman, A. H. E. Müller, O. Ikkala and R. H. A. Ras, "Color tunability and electrochemiluminescence of silver nanoclusters" Angewandte Chemie International Edition 48, 2122 (2009).

13. P. Kunwar, J. Hassinen, G. Bautista, R. H. A. Ras, and J. Toivonen, "Direct Laser Writing of Photostable Fluorescent Silver Nanoclusters in Polymer Films" ACS Nano 8, 11165-11171 (2014).

14. J. Li, J.-J. Zhu, and K. Xu, "Fluorescent metal nanoclusters: From synthesis to applications" TrAC Trends in Analaytical Chemistry 58, 90-98 (2014)

15. G. Schmid, and L. F. Chi, "Metal Clusters and Colloids" Advanced Materials 10, 515-526 (1998).

16. J. Zheng, J. T. Petty, and R. M. Dickson, "High Quantum Yield Blue Emission from Water-Soluble $\mathrm{Au}_{8}$ Nanodots" Journal of American Chemical Society 125, 7780-7781 (2003)

17. E. G. Gwinn, P. O'Neill, A. J. Guerrero, D. Bouwmeester, and D. K. Fygenson, "Sequence-Dependent Fluorescence of DNA-Hosted Silver Nanoclusters" Advanced Materials 20, 279-283 (2008).

18. B. Corain, G. Schmid, and N. Toshima, Metal Nanoclusters in Catalysis and Materials Science (Elsevier, Amsterdam, 2008) pp. 22.
19. P. Jena and A. W. Castleman, Nanoclusters A Bridge across Disciplines (Elsevier, Amsterdam, 2010) p. 28.

20. X. L. Guével, B. Hötzer, G. Jung, K. Hollemeyer, V. Trouillet, and M. Schneider, "Formation of Fluorescent Metal (Au, Ag) Nanoclusters Capped in Bovine Serum Albumin Followed by Fluorescence and Spectroscopy" The Journal of Physical Chemistry C 115, 10955-10963 (2011).

21. S. Kawata, H. Sung, T. Tanaka, and K. Takada, "Finer features for functional microdevices" Nature 412, 697(2001).

22. P. Kunwar, J. Toivonen, M. Kauranen, and G. Bautista, "Third-harmonic generation imaging of three-dimensional microstructures fabricated by photopolymerization" Optics Express 24, 9353-9358 (2016).

23. M. Bellec, A. Royon, K. Bourhis, J. Choi, B. Bousquet, M. Treguer, T. Cardinal, J.-J. Videau, M. Richardson, and L. Canioni, "3D patterning at the nanoscale of fluorescent emitters in glass" The Journal of Physical Chemistry C 114, 15584 (2010)

24. G. De Cremer, B. F. Sels, J.-I. Hotta, M. B. J. Roeffaers, E. Bartholomeeusen, E. Coutiño-Gonzalez, V. Valtchev, D. E. De Vos, T. Vosch, and J. Hofkens, "Optical Encoding of Silver Zeolite Microcarriers" Advanced Materials 22, 957-960 (2010).

25. P. Kunwar, J. Hassinen, G. Bautista, R. H. A. Ras, and J. Toivonen, "Submicron scale patterning of fluorescent silver nanoclusters using lowpower laser" Scientific reports 6, 23998(2016).

26. P. Kunwar, L. Turquet, J. Hassinen, R.H. A. Ras, J. Toivonen, and G. Bautista, "Holographic patterning of fluorescent microstructures comprising silver nanoclusters" Optical Materials Express 6, 946-951 (2016).

27. B. Kang, S. Han, J. Kim, S. Ko, and M. Yang, "One-Step Fabrication of Copper Electrode by Laser-Induced Direct Local Reduction and Agglomeration of Copper Oxide Nanoparticle" J. Phys. Chem. C 115, 23664-23670 (2011)

28. E. Blasco, J. Müller, P. Müller, V. Trouillet, M. Schön, T. Scherer, C. B.Kowollik, and M. Wegener "Fabrication of Conductive 3D Gold-Containing Microstructures via Direct Laser Writing," Advanced Materials 28, 35923595 (2016)

29. K. Vora, S. Y. Kang, S. Shukla and E. Mazur, "Fabrication of disconnected three-dimensional silver nanostructures in a polymer matrix"Applied Physics Letters, 100, 063120 (2012).

30. J. Wang and L. Ye, "Structure and properties of polyvinyl alcohol/polyurethane blends" Composites: Part B 69, 389-396 (2015).

31. R. Chandra and R. Rustigi, "Biodegradable polymers" Progress in Polymer Science 23, 1273-1335 (1998).

32. M. I. Baker, S. P. Walsh, Z. Schwartz, and B. D. Boyan, "A review of polyvinyl alcohol and its uses in cartilage and orthopedic applications" Journal of Biomedical Materials Research Part B 100B, 1451-1457 (2012).

33. S. Ghoshal, P. Denner, S. Stapf, and C. Mattea, "Study of the Formation of Poly(vinyl alcohol) Films" Macromolecules 45, 1913-1923 (2012).

34. N. Mahanta and S. Valiyaveettil, "In situ preparation of silver nanoparticles on biocompatible methacrylated poly(vinyl alcohol) and cellulose based polymeric nanofibers" RSC Advances 2, 11389 (2012).

35. D. Pencheva, R. Bryaskova, and T. Kantardjiev, "Polyvinyl alcohol/silver nanoparticles (PVA/AgNps) as a model for testing the biological activity of hybrid materials with included silver nanoparticles" Materials Science and Engineering: C 32, 2048-2051 (2012). 
36. E. Filippo, A. Serra, and D. Manno, "Poly(vinyl alcohol) capped silver nanoparticles as localized surface plasmon resonance-based hydrogen peroxide sensor" Sensors and Actuator B: Chemical 138, 625-630 (2009).

37. L. Peyser-Capadona, J. Zheng, J. I. González, T.-H. Lee, S. A. Patel, and R. M. Dickson, "Nanoparticle-Free Single Molecule Anti-Stokes Raman Spectroscopy" Physical Review Letters 94, 058301 (2005).

38. L. Shang and S. Dong, "Facile preparation of water-soluble fluorescent silver nanoclusters using a polyelectrolyte template" Chemical Communications, 1088-1090 (2008).

39. J. Zheng, Y. Ding, B. Z. Tian, Z. L. Wang and X. W. Zhuang, "Luminescent and Raman active silver nanoparticles with polycrystalline structure" J. Am. Chem. Soc. 130, 10472-10473 (2008).

40. L. Maretti, P. S. Billone, Y. Liu and J. C. Scaiano, "Facile Photochemical Synthesis and Characterization of Highly Fluorescent Silver Nanoparticles" J. Am. Chem. Soc. 131, 13972-13980 (2009).

41. R. C. Willson, and A. V. Mordvinov, "Secular total solar irradiance trend during solar cycles" Geophys. Res. Lett. 30, 21-23 (2003). 